\title{
CHILD POVERTY IN ISTANBUL: AN ANALYSIS IN THE NEIGHBORHOOD SCALE*
}

\author{
Murat ŞEKER ${ }^{1}$
}

\author{
Hakan BEKTAŞ ${ }^{2}$
}

\begin{abstract}
In this study, the neighborhoods determined in Istanbul will be subjected to clustering analysis with the socioeconomic data set formed and the number of children in the neighborhood scale will be estimated. At the same time, factors affecting child poverty in Istanbul and their impact coefficients will be determined by logistic regression model. Thus, the impact of the change in the factors affecting child poverty will be investigated.
\end{abstract}

Keywords: child poverty, neighborhood, index, logistic regression

JEL Code: I32, C35.

\section{Introduction}

In the literature, the concept of poverty is defined with different perspectives. In 1990 the World Bank to identify his "absolute poverty" and "relative poverty" was coined concepts. The situation below the level of income determined based on the minimum needs of the person to sustain life is called absolute poverty. Although biological needs were taken into consideration in the beginning, the scope of absolute poverty was expanded by taking into account the access to basic services such as education, shelter and health. (World Bank, 1990; 1995) Relative poverty is defined as the average income level of the society below the determined rate.

The concept of child poverty, which constitutes the starting point of this study, involves the deprivation of opportunities for the growth and development of children living in poverty. In addition, it is common for children growing up in poverty to be among the adult poor in the future. (Corcoran, 1995; Lichter, 1997)

\section{The Concept of Child Poverty}

Child poverty has become a subject of social policy with the 19th century and it has been encouraged to prevent child poverty by the efforts of public power in this field. (Platt, 2005)

According to UNICEF's definition of child poverty in OECD countries; a child should be considered as poor if he or she is less than half of the median income that children growing up in the community may assume, when the resources are justly distributed in the family. (UNICEF, 2005)

In The State of the World's Children 2005 report, UNICEF said: "Life, growth and development

\footnotetext{
* This study was funded by Scientific Research Projects Coordination Unit of Istanbul University. Project number: SBG-2019-33390.

1 Prof. Dr., Istanbul University Faculty of Economics, mseker@istanbul.edu.tr (corresponding author)

2 Dr., Istanbul University Faculty of Economics, hbektas@istanbul.edu.tr
} 
of the necessary financial, spiritual and emotional resources is lack of. Children living in poverty live in a way deprived of the necessary material, spiritual and emotional resources in terms of their life, growth and development, so that they cannot benefit from their rights, they cannot fully realize their potential and they do not participate in society as full and equal members." (UNICEF, 2005)

In 2005, UNICEF published 1 million 450 thousand children and $51 \%$ of the interviewed children were deprived of at least two and more of their basic needs. While 10 percent of the children born in developing countries are poor, in the developed countries, although the rate of child poverty is low, it is another result of the study that the structural solutions for this problem have not been developed.

When the international and national statistics are examined, it is observed that child poverty is at a higher level than adult poverty. (Brooks et. al., 1997) For example, in Turkey from 2002 to 2007 under 15 years of absolute poverty, the poverty rate was higher for all individuals. Turkey between fertility and poverty when viewed in private is possible to say that there is a linear relationship. This situation is clearly observed when only the statistics are explained, the household average size increases as income decreases. Therefore, this is one of the main reasons for the rate of child poverty to be higher than the general poverty rate. (TurkStat, 2007)

Among the findings in many studies where child poverty is low, education level decreases, health conditions worsen, pregnancy is observed at a young age, substance dependence is frequent, tendency to commit crime and long-term dependence on state aid are observed. (UNICEF, 2006)

In a study on the causes of child poverty, parent unemployment, low income, lack of income support and household size have been shown to increase the risk of child poverty. (Gauthier, 1999; Bradbury et al., 2001). In the study, it was found that the family structure was important for the poverty of the household according to the size of the household, and the fact that it was one parent was found to be effective on poverty. (Gauthier, 1999)

There are some parameters frequently used in the literature to determine child poverty. Average household income, monthly household expenditure, infant and child mortality rates, low birth weight infant rates (children born to underweight), access to education, preschool education rate, schooling rate, net schooling level in primary education, child labor child poverty is tried to be estimated.

\section{Empirical Analysis and Results}

In a study conducted within the scope of Istanbul, Gini Coefficient was calculated considering the scale of the neighborhood and it was found as 0.405 . Among the $20 \%$ of the population with the highest income in Istanbul and the lowest income with $20 \%$, the share of the difference in income was determined as 7.7 times. 10.3 times in the comparison of the cut is indicated. In this study, how the share of income in Istanbul was analyzed. Accordingly, $5 \%$ of the population with the highest income receives $21 \%$ of the total income. The $10 \%$ share with the highest income receives one-third of the total revenue, while the $20 \%$ with the highest income has half of the total revenue. Therefore, one fifth of the people living in Istanbul receive half of the income, while the remaining $80 \%$ share the other half of the income. (Şeker, et. al.; 2017) 
According to the 2018 data, the population of children aged 0-4 is 1.152.651 in Istanbul and the population below the age of 15 is 3.331.960. The percentage of children who constitute $22.1 \%$ of Istanbul's total population is in poverty is an important question. Arnavutköy, Sultanbeyli, Esenyurt, Sancaktepe and Sultangazi are among the districts where children's population is located.

In this analysis, the number of children in the neighborhood scale in the neighborhood scale in Istanbul is estimated; Factors affecting child poverty and impact factors will be determined by logistic regression model.

\subsection{Methodology}

In this analysis, literature review was conducted to determine the factors affecting child poverty. Commonly used variables were found in the literature; secondary data sources are referenced. At this stage, taking into account the variables of the relationship between the variables and the accessibility of variables; the variables to be included in the study were determined. In addition to this, the districts which had previously been in the village status in Istanbul and then turned into neighborhoods were excluded. Because child poverty was not directly measured, it was measured indirectly using the variables mentioned. In other words, child poverty is a latent variable. Therefore, by taking the average of the observed variables, child poverty variable is derived. Thus, child poverty scores and child poverty index were established. Since the measurement units of the variables observed at this stage were different from each other, the index score was calculated after these variables were standardized.

When the child poverty series were examined, normal distribution was investigated. At this stage, Kolmogorov-Smirnov test was used. The basic hypothesis of this test indicates that the variable is normally distributed. In this study, the basic hypothesis was not rejected at a level of 0.05 significance. In other words, the series conforms to normal distribution. The series was then categorized using mean and standard deviation. Child poverty index score was assumed to be normal in neighborhoods within a standard deviation range from the mean of the series. Neighborhoods outside this range have been categorized as poor and in good condition in terms of child poverty. Therefore, the neighborhoods examined were grouped.

When neighborhoods in Istanbul are grouped in terms of child poverty, these groups will show child poverty levels. Regression analysis will be carried out to estimate the impact of factors affecting child poverty at the neighborhood level in Istanbul. The dependent variable of this analysis will be the poverty levels obtained by clustering analysis. The regression analysis will be used to model the relationship between the qualitative dependent variable and the factors affecting it. At this stage, logistic regression model will be preferred due to the fact that the dependent variable is qualitative. The logistic regression model is also an association method within the family of regression models and is used when the dependent variable is a qualitative variable. In other words, the dependent variable in the logistic regression model carries a qualitative (categorical) variable. The method is divided into sub-types according to whether the qualitative variable in question is binary, multiple or sequential. For example; If the dependent variable has two responses, binary logistic regression is applied. In addition, sequential logistic regression analysis is preferred if there is a sort relationship between the responses of the dependent variable. The purpose of logistic regression analysis is to estimate the value of the 
categorically dependent variable, in fact it is the, membership index estimate for two or more groups that are attempted here. Accordingly, it can be said that one of the objectives of the analysis is to investigate the relationships between classification and the other dependent and independent variables.

In this study, the relationships between dependent and independent variables will be investigated. Logistic regression analysis does not require a linear relationship between independent and dependent variables; there may be an exponential or polynomial relationship. Logistic regression assumes a logitic relationship between dependent and independent variables; hence logistic regression can produce nonlinear models. Unlike linear regression analysis, logistic regression analysis does not require assumptions that should be met by researchers related to distribution. Therefore, it can be said that logistic regression is much more flexible than linear regression analysis. Hypothesis tests and model goodness measurements used in logistic regression analysis are similar to classical regression. Logistic regression is based on goodness of fit tests as a tool for assessing model-data compliance. Like multiple linear regression, logistic regression is highly sensitive to the high correlation between independent variables. If there is a high degree of correlation between the independent variables, multiple connection problems are encountered. If there is a multiple connection problem between the variables included in the analysis, it is recommended to remove one or more variables from the model in order to disable this problem. In the logistic regression analysis, it is necessary to avoid the least number of observations, since the highest likelihood method is used in obtaining the coefficients as opposed to the least squares method. In addition, one of the points differentiated from linear regression analysis is that the odds ratio (Odds Ratio), which is not the predicted coefficient in logistic regression model, is used in the interpretation of the model. The sign of the predicted coefficients in the model (positive or negative) indicates the direction of the relationship. The positive coefficient increases the probability of predicting, while the negative coefficient decreases (Çokluk, 2010).

\subsection{Data}

In this study, a demographic analysis of the neighborhoods where children live in Istanbul will be revealed. The socioeconomic outlook of the identified neighborhoods will be determined on the basis of secondary data. Thus, the relationship between the socioeconomic level of the neighborhoods and the proportion of children will be seen and the child poverty map of Istanbul will be drawn. Apart from this demographic analysis, the same data set will be established at the 699 neighborhood level in Istanbul and the factors affecting child poverty will be determined by the regression model to be established. The neighborhood scale parameters used in the analysis are as follows:

- Average size of households

- Age dependency ratio

- Household education level

- Access to health care and service quality (number of patients per doctor)

- Access to education and service quality (Number of students per teacher and classrooms)

- Sale and rental housing prices

- Demand density (Market density)

- Child Population 


\subsection{Results}

The derived child poverty index series is categorized by using the interval method as it conforms to the normal distribution.

Table 1. Child Poverty Index - Neighborhood Segment

\begin{tabular}{|c|c|c|c|}
\hline & Neighborhoods & Child Population (0-15 age) & $\begin{array}{c}\text { Child Poverty Population/ } \\
\text { Total Child Population (\%) }\end{array}$ \\
\hline High Child Poverty & 96 & 590.651 & 18,1 \\
\hline Middle Child Poverty & 500 & 2.320 .771 & 71,3 \\
\hline Low Poverty & 103 & 346.169 & 10,6 \\
\hline Total & 699 & 3.257 .591 & 100,0 \\
\hline
\end{tabular}

The dependent variable of the regression model is the index of child poverty. The high value of this index shows that child poverty is low. As you will remember; The index series is divided into 3 categories according to the interval method. Therefore, since the dependent variable is categorical, logistic regression analysis is used from qualitative dependent models. Since the responses of the dependent variable were sequential (low, medium, high), the model was estimated by sequential logistic regression analysis. However, it was found that the assumption of parallelism, which is one of the assumptions of the ordinal logistic regression model, was not provided. As a result, the dependent variable is re-encoded. In other words, the responses of the dependent variable; low and medium (medium + high). Binary logistic regression analysis was applied because the response level of the dependent variable became binary.

Table 2. Variables in the Equation

\begin{tabular}{|c|c|c|c|c|c|c|c|}
\hline & & B & S.E. & Wald & $d f$ & Sig. & $\operatorname{Exp}(B)$ \\
\hline \multirow[t]{4}{*}{ Step $1^{\mathrm{a}}$} & Income level & ,490 & 109 & 20,063 & 1 & 000 & 1,632 \\
\hline & Maternal education level & 921 & ,483 & 3,646 & 1 & 005 & 2,513 \\
\hline & Average size of households &,- 777 & ,285 & 7,451 & 1 & ,006 & ,460 \\
\hline & Constant & 1,117 & ,485 & 5,305 & 1 & 021 & 3,055 \\
\hline
\end{tabular}

a. Variable(s) entered on step 1: Income level, Mother education level, Average size of households.

According to the results of the analysis, a one-unit increase in the income variable increases the likelihood of a decrease in child poverty by 1.6 times. The mother-child change in education level increases the probability of child poverty reduction by 2.5 times. Each unit increase in the household average size variable increases the likelihood of child poverty by 2.17 times.

\section{Conclusion}

In this study, the concept of child poverty was examined at the neighborhood level in Istanbul. As a result of the analyzes conducted with 699 neighborhoods in Istanbul, high level of child poverty was detected in 96 neighborhoods. On the other hand, 103 neighborhoods are neighborhoods where child poverty is very low. These analyzes of the neighborhood scale in Istanbul show that the rate of child poverty is $18 \%$ in Istanbul. 
Three factors highlighted the factors affecting child poverty. Maternal education level is one of the main factors affecting child poverty. The household average size and income level are also determinants of child poverty. The higher the level of maternal education, the lower the size of households and the higher the income level, the lower the level of child poverty.

\section{References}

Bradbury, B., Jenkins, S.P., Micklewright J. (2001). The Dynamics of Child Poverty in Industrialized Countries, Cambridge University Press, Cambridge.

Brooks-Gunn, J., Duncan, J.G. (1997). Consequences of Growing up Poor, Russell Sage Foundation: New York.

Corcoran, M. (1995). "Rags to rags: Poverty and mobility in the United States", Annual Review of Sociology, 21, pp. 237-267.

Çokluk, Ömay (2010). "Lojistik Regresyon Analizi: Kavram ve Uygulama”, Kuram ve Uygulamada Eğitim Bilimleri, 10(3), 1357-1407.

Gauthier, A. H. (1999). "Historical trends in state support for families in Europe (post-1945)”, Children and Youth Services Review, 21(11-12), pp. 937-65.

Lichter, D.T. (1997). "Poverty and Inequality Among Children”, Annual Review of Sociology, 23, pp. 121-145.

Platt, L. (2005). Discovering Child Poverty, Policy Pres: Bristol.

Şeker, M. vd. (2017). Mahallem İstanbul, iÜ-iSTKA Yayını, İstanbul.

TURKSTAT (Türkiye İstatistik Kurumu). (2007). Hane Halkı Bütçe Anketi Istatistikleri, Ankara.

UNICEF (2005). The State of the World's Children 2005, New York.

UNICEF (2006). Çocuk Yoksulluğunun Önlenmesi Konferansı Raporu, Ankara.

World Bank (1990). World Development Report: Poverty, New York: Oxford University Press.

World Bank (1995). World Development Report:Workers in an Integrating World, New York: Oxford University Press. 